\title{
Very Rapid Prototyping of Wearable Computers: A Case Study of VuMan 3 Custom versus Off-the-Shelf Design Methodologies
}

\author{
ASIM SMAILAGIC \\ asim@cs.cmu.edu \\ Institute for Complex Engineered Systems, Carnegie Mellon University, 5000 Forbes Ave, \\ Pittsburgh, Pennsylvania, 15213, USA \\ DANIEL P. SIEWIOREK \\ dps@cs.cmu.edu \\ Institute for Complex Engineered Systems, Carnegie Mellon University, 5000 Forbes Ave, \\ Pittsburgh, Pennsylvania, 15213, USA \\ RICHARD MARTIN \\ martin@cs.cmu.edu \\ Institute for Complex Engineered Systems, Carnegie Mellon University, 5000 Forbes Ave, \\ Pittsburgh, Pennsylvania, 15213, USA \\ JOHN STIVORIC \\ js1y@andrew.cmu.edu \\ Institute for Complex Engineered Systems, Carnegie Mellon University, 5000 Forbes Ave, \\ Pittsburgh, Pennsylvania, 15213, USA
}

\begin{abstract}
The Wearable Computer Project is a testbed integrating research on rapid design and prototyping. Based on representative examples from six generations of wearable computers, the paper focuses on the differences in rapid prototyping using custom design versus off-the-shelf components. The attributes characterizing these two design styles are defined and illustrated by experimental measurements. The off-the-shelf approach required ten times the overhead, 30\% more cost, fifty times the storage resources, $20 \%$ more effort, five times more power, but $30 \%$ less effort to port software than the embedded approach. An evaluation of the Vuman 3 design is presented to show its superior advantages in comparison to the off-the-shelf approach.
\end{abstract}

Keywords: Rapid prototyping, embedded system design, wearable computers.

\section{Introduction}

Exponential advances in technology require rapid prototyping as an essential aspect of design and manufacturing. Competitiveness in the global economy requires rapid response to changing market demands, as well as capturing rapid technological advances and translating them into new products. Rapid prototyping is an example of a group of CAD/CAM methodologies which shorten the design/manufacturing cycle. There is no single rapid prototyping technology which addresses all the challenges posed by product development. Success requires innovation and incorporation of a broad range of tech ${ }^{1}$ nologies covering scale (micro to macro), domains (electrical, mechanical, software), media (physical and virtual) and resources (local and distributed). Carnegie Mellon University has addressed many of these issues in research on rapid prototyping of electronic/mechanical systems.

This paper illustrates how the Engineering Design Research Center is using the wearable computer project as a testbed in which to perform research on rapid design and prototyping. Through this process we have learned about rapid prototyping education and practice.

Based on representative examples from six generations of wearable computers, the paper focuses on rapid prototyping of custom designed vs. off-the-shelf systems. As running examples we will use the Navigator 1 general purpose wearable computer and the VuMan 3 custom designed wearable computer, as these two computers are comparable in functionality. In the next section we will present the characteristics of Navigator 1 and VuMan 3 wearable computers.

Journal on Design Automation for Embedded Systems, Kluwer Academic Publishers, Vol. 3, No. 3, 1998 


\section{Case Study: VuMan 3 and Navigator 1 Wearable Computers}

Carnegie Mellon University has rapidly designed and prototyped six generations of wearable computers: VuMan 1 [1], VuMan 2 [2], Navigator 1 [3], VuMan MA [4], VuMan 3, and Navigator 2. Figure 1 presents the main characteristics of the CMU wearable computers.

These generations of wearable computers could be classified into two generic classes of systems: custom designed (VuMan) and designed by composition systems (Navigator), using mainly off-the-shelf components. In addition to custom designed electronics and mechanical enclosure/ interface, VuMan wearable computers have also adopted an embedded, customdesigned approach to the software information system. In Navigator, a modular "mix-and-match" architecture allows multiple configurations increasing the general purpose nature of the wearable computer.

An Interdisciplinary Concurrent Design Methodology (ICDM) [3], [5], [6], [7] has been evolving, as we design new artifacts and processes. The goal of the design methodology is to allow as much concurrency as possible in the design process. Concurrency is sought in both time and resources. Time is divided into phases. Activities within a phase proceed in parallel but are synchronized at phase boundaries. Resources consist of personnel, hardware platforms and communications. Personnel resources are dynamically allocated to groups that focus on specific problems. As a result of this methodology, we have achieved a four months design cycle for each new generation of wearable computers. The cycle time of the new products is ideally suited to the academic semester. Figure 2 illustrates the iterative nature of user centered design to elicit feedback during the design cycle. Student designers initially visit the user site for a walk-through of the intended application. A second visit after a month of design elicits responses to story boards of the use of the artifact and the information content on the computer screen. After the second month a software mock-up of the system running on a previous generation wearable computer is evaluated in the end-user's application. During the third month, a prototype of the system
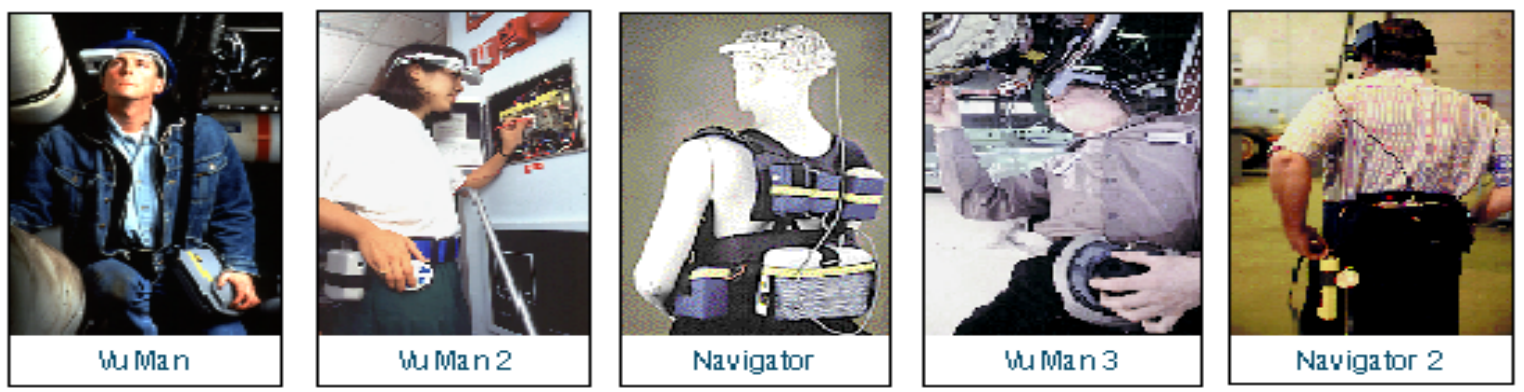

\begin{tabular}{|c|c|c|c|c|c|}
\hline Artifact Specifications & Vu Man 1 & Mu Man 2 & Navigator 1 & Vu Man 3 & Navigator 2 \\
\hline Dadimary Dab & Aug 91 & $\mathrm{Dac} 92$ & June 93 & $D=094$ & Juhy 95 \\
\hline Number of unit & 30 & 0 & 3 & 20 & 日 \\
\hline Emboddad/GP & ambodidad & ambodidad & ponald pupces & ambodidad & ponad pupces \\
\hline Derign S, to & samiaustom & fulpaustom & dasign by composifen & fulpaustom & samicustom \\
\hline \# of custom boards/chip couml & $1 / 24$ & $1 / 5$ & $3 / 15$ & $2 / 10$ & $2 / 29$ \\
\hline \# of dfHhoshof boad & 1 & 0 & 5 & $\mathrm{O}$ & 2 \\
\hline Ines of code & 1800 & 4700 & 38000 & 12000 & 88000 \\
\hline Procoessor & 8018日- BMHz & 80C18日- $13 \mathrm{MHz}$ & $80386-25 \mathrm{MHz}$ & BO3GGEX-20 MHz & $4865 x-33+D S P$ \\
\hline RAW/Nbnvelerb storage & 日 KB - $512 \mathrm{~KB}$ & $512 \mathrm{kB}-1 \mathrm{MB}$ & $16 \mathrm{MB}-\mathrm{A5MB}$ & $1 \mathrm{MB}-42 \mathrm{OMB}$ & $12 \mathrm{MB}-420 \mathrm{MB}$ \\
\hline Inpert & 3tarkn & 3tarkon & spooch/mouse & robly w/bulan & spooch / ippoict \\
\hline Depby rascdulion & $720 \times 2 B O$ & $720 \times 280$ & $720 \times 280$ & $720 \times 280$ & 6400480 \\
\hline Dmansions linchod) & $10.5 \times 5.25 \times 3$ & $4.75 \times 4.5 \times 1.37$ & $7.25 \times 10 \times 3$ & $5 \times 6.25 \times 2$ & $5.8 \times 10.7 \times 3.2$ \\
\hline Power MD & 3.B & 1.1 & 7.5 & 2 & 7.5 \\
\hline Waigh |bs) & 3.3 & 0.5 & 9 & 1.75 & 4 \\
\hline
\end{tabular}

Figure 1. The CMU Wearable Computers

receives a further user critique. The final system is delivered after the fourth month for field trial evaluation.

Based on representative examples from these six generations of wearable computers, we have observed a clear impact that the design style (custom vs. off-the-shelf) has on the cost and efficiency of our rapid design/prototyping process. The major attributes are the following:

- Overhead factor

- Relative cost

- Person power 
- Software portability

- Power management

- Storage requirements

These attributes are defined in the next section. As running examples we will use the Navigator 1 general purpose wearable computer and the VuMan 3 custom designed wearable computer. Their major characteristics are summarized in Figure 1.

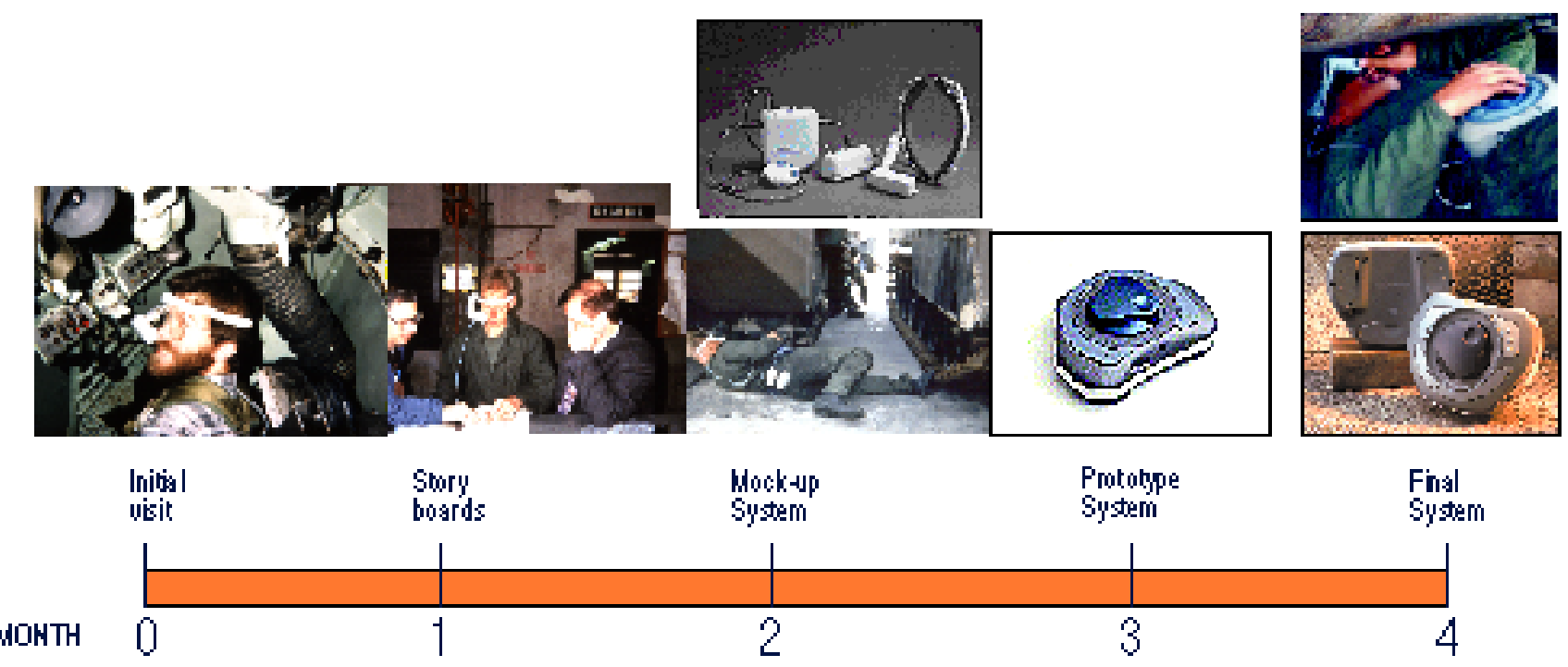

Figure 2. Four Month Design Cycle.

\subsection{VuMan 3}

VuMan 3 is a fully custom design. The initial VuMan 3 application is as a wearable maintenance assistant, allowing users to display and interact with reference manuals in the form of hypertext documents. The design culminated in a 386EX based VuMan 3 wearable computer, with two custom designed printed circuit boards (PCBs), a novel input device (Dial), reconfigurable input controller, intelligent power management embedded into an environmental sealed housing; and a smart docking station. The processor provided added functionality such as on-chip integrated power management and two DMA channels. The programmable microcontrollers for input/output allow reconfiguration of the user interface (e.g. mouse, dial, or joystick) and power control that selectively turns off unused chips. The second custom designed PCB is a PCMCIA controller board supporting two slots. The head-mounted display design is enhanced with a customized headband.

After exploring the implications on the housing configuration it was decided to decrease the footprint of the design by increasing its thickness with a two board design, the main processor board and a PCMCIA controller board, Figure 3. The PCMCIA Card Controller Chip minimized chip count of the interface between the processor ISA bus and the PC Card socket.

The user task analysis yielded the following design constraints - the environmental sealed housing, an input device that could be operated independent of orientation and with gloves, and embedded in the housing. A novel customized input device, the rotary dial, emerged as the central organizing motif of the design. A variety of different sizes and forms for the dial was presented to our users, Figure 4, and based upon their feedback design proceeded with making the wooden mock-up to visualize the housing, to 2D CAD Proengineer model and refined stereolithography (SLA) model. 


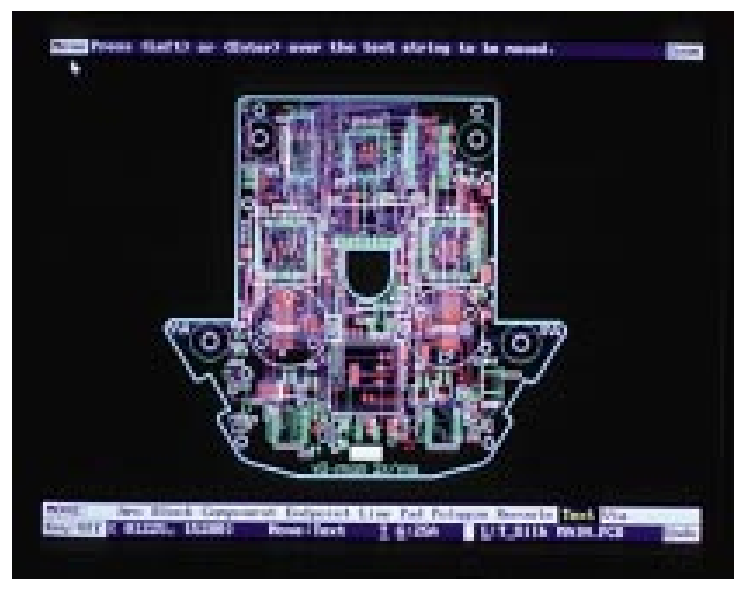

Figure 3. Main processor board

VuMan 3 provides modularity via PCMCIA card options. A tight integration of the new forms based VuMan Hypertext Language (VHTL), as the basis of the application software implementation, and rotary dial lead to a new user interface paradigm: circular input, circular visualization. The dial required a rethinking of the user interface to map an one-dimensional input device to a two-dimensional selection surface.

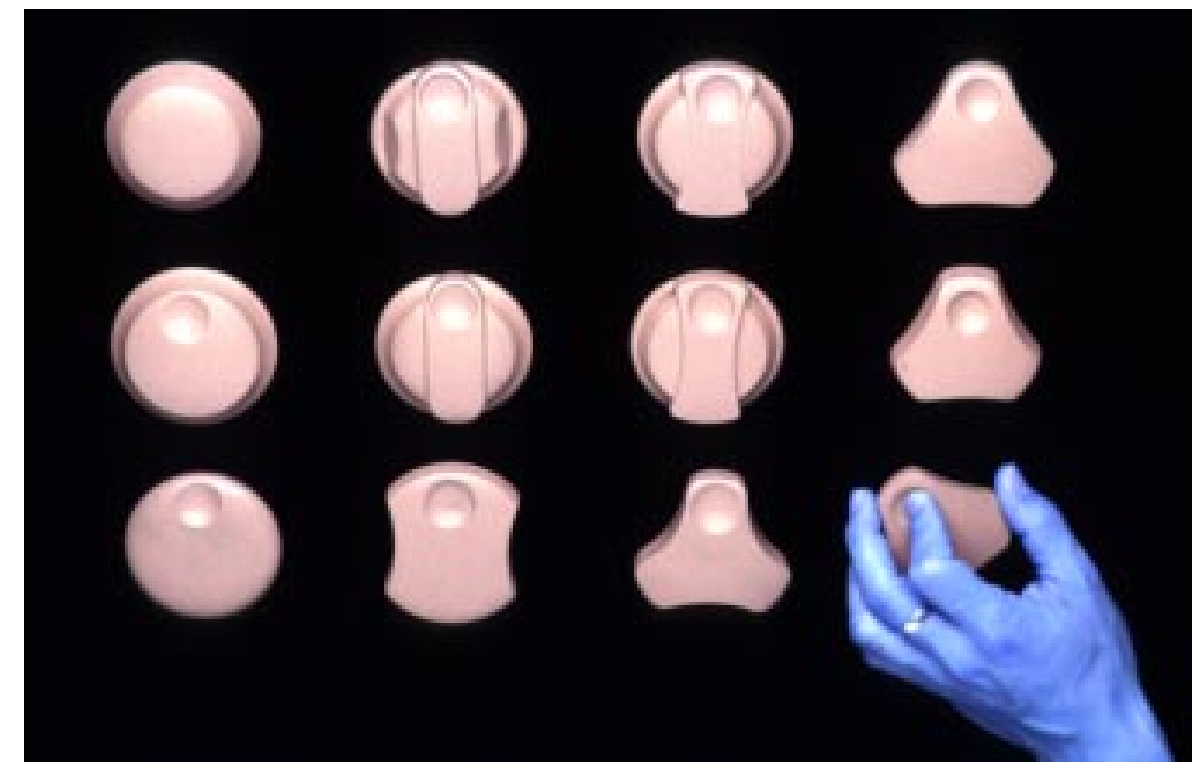

Figure 4. Different forms for the input dial.

\subsection{Navigator 1}

Navigator 1 is a general purpose computer consisting of off-the-shelf boards: an 386SX processor card, Private Eye interface [8], VGA controller, A/D card, GPS (global position sensing) card, modem, disk, and mouse controller. The custom boards in Navigator include the GPS interface, on-set of speech detection, and power control. The initial application was campus navigation. Navigator can use speech as input, allowing completely hands-free operation. Navigator 1's speech recognition system is speaker-independent [9], has a 200 word vocabulary, and runs at about eight times real time. A mouse is also available, in case that speech is undesirable. Navigator 1 runs the Mach operating system [10], allowing applications to be developed on a UNIX workstation and then transferred to the Navigator 1 platform. Software developers can use the standard UNIX environment, such as X Windows [11] and Shell scripts, in their applications. Modularity of design was a very important concern. Navigator 1 is composed of modular subsystems, such as head-mounted display, global position sensing (GPS), and telecommunication. A study of the Navigator 1 produced a set of techniques that reduced the power consumption of the off-the-shelf boards by $50 \%$ [12]. 


\section{Evaluation of the two Design Styles}

We will now evaluate the impact of the two design styles on six major design attributes.

\subsection{Overhead Factor}

The overhead factor is defined as

(number of features available - number of features used)/number of features available.

Table 1 lists the specifications and major features of the off-the-shelf boards used in Navigator 1, and illustrates the mismatch of requirements between desktop and mobile hardware [12]. The design was meant to be a proof of concept, so offthe-shelf boards were used to minimize electronic design time and the probability of electronic design errors. Only one of the off-the-shelf boards, the CPU motherboard, was designed for mobile use. The analog-to-digital (A/D) conversion board and the Private Eye board were intended for use in desktop PCs. Neither of these boards were designed with mobility or power consumption in mind.

Table 2 shows the specifications and major feature of the three custom designed boards in VuMan 3: main processor board, the PCMCIA controller board, and the docking station board, which acts as an input/output processor. A smart docking station monitors the use of the $\mathrm{NiCd}$ rechargeable batteries and also acts as a communication link to a logistic computer system, in order to upload the inspection data. Using the data in Table 1 the overhead factor for Navigator 1 is calculated as $56.5 \%$, and for VuMan 3 as $5.6 \%$

\begin{tabular}{|c|c|c|c|}
\hline Board & Features Available & Features Utilized & Power Requirements \\
\hline $\begin{array}{l}\text { Ampro Little- } \\
\text { Board 386SX }\end{array}$ & $\begin{array}{l}\text { - Intel 386SX } \\
\text { Processor } \\
\text { - System Management } \\
\text { Mode (SSM) } \\
\text { - Math coprocessor } \\
\text { - IDE HD Interface } \\
\text { - up to } 16 \text { MB DRAM } \\
\text { - Serial Ports (2) } \\
\text { - Parallel Port } \\
\text { - PC 104 Bus } \\
\text { - Watchdog Timer } \\
\text { - Keyboard Connector } \\
\text { - SCSI Interface } \\
\text { - Floppy Drive } \\
\text { Controller }\end{array}$ & $\begin{array}{l}\text { - Intel 386SX } \\
\text { Processor } \\
\text { - System Management } \\
\text { Mode (SSM) } \\
\text { - Math coprocessor } \\
\text { - IDE HD Interface } \\
\text { - 16 MB DRAM } \\
\text { - Serial Ports (1) } \\
\text { - Parallel Port } \\
\text { - PC } 104 \text { Bus }\end{array}$ & $+5 \mathrm{~V} @ 1.0 \mathrm{~A}$ \\
\hline $\begin{array}{l}\text { Pro Audio-Spec- } \\
\text { trum } 16\end{array}$ & $\begin{array}{l}\text { - Audio Record } \\
\text { - Audio Playback } \\
\text { - Stereo Mixer } \\
\text { - CD ROM Interface } \\
\text { - SoundBlaster } \\
\text { Emulation } \\
\text { - Microphone } \\
\end{array}$ & $\begin{array}{l}\text { - Audio Record } \\
\text { - Microphone }\end{array}$ & not spec-ified \\
\hline Private Eye & $\begin{array}{l}+12 \text { V/ 5V Supply } \\
\text { - CGA mode } \\
\text { - CGE Shadow Mode } \\
\text { - nonCGA Mode }\end{array}$ & $\begin{array}{l}\text { +5V Supply } \\
\text { - nonCGA Mode }\end{array}$ & $+12 \mathrm{~V} @ .24 \mathrm{~A}$ \\
\hline
\end{tabular}

Table 1. Specifications of Off-the-Shelf Boards used in Navigator 1

\subsection{Cost}

Navigator 1's cost represents the cost of the off-the-shelf boards, plus the purchase price of components in quantities of one, plus the total cost of tooling and fabrication for the custom boards divided among the three units produced. The off-the-shelf 
boards include the 80386X processor motherboard, the Private Eye interface, VGA, A/D, Global Position Sensing (GPS), modem, disk, and mouse controller. The custom boards in Navigator include the GPS interface, on-set of speech detection, and power regulation.

VuMan 3's cost includes the purchase price of components in quantities of one, plus the total cost of tooling for the three different printed circuit boards and their fabrication divided among twenty units produced, plus the total cost of tooling and fabrication for housing divided among twenty units produced. A detailed breakdown of the costs, including components and services, as well as the list of suppliers for Navigator 1 and VuMan 3 can be found in [13].

\subsection{Resource Utilization}

An Integral Peripheral's IDE hard disk (75 MB) is used as secondary storage for Navigator 1. The application is a CMU Campus Tour, with speech input. The total disk space used by the initial Navigator 1 system was $62.5 \mathrm{MB}$. Discussions with the operating system group revealed that this was considered to be a minimal configuration.

In an attempt to make a Flash Memory Card a feasible option for the Navigator 1's secondary storage, disk usage was first analyzed, using the UNIX tool du, and then systematically reduced. The initial distribution of disk space is shown by category in Table 3 column 2 [14]. It is clear that the prime consumers of disk space are swap space, system utilities, $X$ Windows, the

\begin{tabular}{|c|c|c|c|}
\hline Board & Features Available & Features Utilized & Power Require-ments \\
\hline $\begin{array}{l}\text { Main Pro- } \\
\text { cessor Board }\end{array}$ & $\begin{array}{l}\text { - Intel 386EX } \\
\text { Processor } \\
\text { - System } \\
\text { Management } \\
\text { Mode (SSM) } \\
\text { - DMA Channel } \\
\text { (1) } \\
\text { - Serial Ports (2) } \\
\text { - Parallel Port } \\
\text { - PIC } \\
\text { Microcontroller } \\
\text { - Real-time Clock } \\
\text { - Serial Number } \\
\text { Chip } \\
\end{array}$ & $\begin{array}{l}\text { - Intel 386EX } \\
\text { Processor } \\
\text { - System } \\
\text { Management } \\
\text { Mode (SSM) } \\
\text { - DMA Channel } \\
\text { (1) } \\
\text { - Serial Ports (2) } \\
\text { - Parallel Port } \\
\text { - PIC } \\
\text { Microcontroller } \\
\text { - Real-time Clock } \\
\text { - Serial Number } \\
\text { Chip } \\
\end{array}$ & $+3.3 \mathrm{~V} @ 1.0 \mathrm{~A}$ \\
\hline $\begin{array}{l}\text { PCMCIA } \\
\text { Controller } \\
\text { Board }\end{array}$ & $\begin{array}{l}\text { - 82365SL PCIC } \\
\text { Chip } \\
\text { - four buffers }\end{array}$ & $\begin{array}{l}\text { - 82365SL PCIC } \\
\text { Chip } \\
\text { - four buffers }\end{array}$ & $\begin{array}{l}+5 \mathrm{~V} @ \text { current not } \\
\text { specified }\end{array}$ \\
\hline $\begin{array}{l}\text { Dock-ing } \\
\text { Station } \\
\text { Board }\end{array}$ & $\begin{array}{l}\text { - 8-bit D/A } \\
\text { Converter } \\
\text { - 8-bit A/D } \\
\text { Converter } \\
\text { - PIC } \\
\text { Microcontroller } \\
\text { - Watchdog timer } \\
\text { - Powersaving } \\
\text { Sleep Mode }\end{array}$ & $\begin{array}{l}\text { - 8-bit D/A } \\
\text { Converter } \\
\text { - 8-bit A/D } \\
\text { Converter } \\
\text { - PIC } \\
\text { Microcontroller } \\
\text { - Watchdog timer } \\
\text { - Powersaving } \\
\text { Sleep Mode }\end{array}$ & $\begin{array}{l}+5 \mathrm{~V} @ \text { current not } \\
\text { specified }\end{array}$ \\
\hline
\end{tabular}

Table 2. Specifications of Custom Boards used in Navigator 1

Campus Tour Application, and miscellaneous data. By condensing these areas in particular, a total of $45.5 \mathrm{MB}$ of disk requirements were eliminated, for a total saving of 73\%. The final distribution of disk usage is shown in Table 3 column 3.

Much of the savings in disk space was accomplished by eliminating unneeded data files that had accumulated over time and by shrinking the unnecessarily large swap space. However, the largest fraction of space was retrieved by evaluating what tasks are likely to be performed on a wearable computer and eliminating space consumed by files serving other functions. For example, compilation can be done on a desktop machine and the binary then downloaded to the wearable unit; thus all files having to do with compilation were eliminated. The end result was a configuration that allowed the system to run on a Flash Memory Card with limited space. 


\begin{tabular}{|l|l|l|}
\hline Category & Initial Space [MB] & Final Space [MB] \\
\hline Kernal & 2.2 & 0.6 \\
\hline UNIX Server & 2.9 & 1.2 \\
\hline Swap Space & 10.0 & 2.0 \\
\hline System Binaries & 3.0 & 1.0 \\
\hline System Utilities & 10.6 & 1.2 \\
\hline X Windows & 10.1 & 5.3 \\
\hline Campus Tour Application & 9.6 & 5.5 \\
\hline Other & 14.1 & 0.2 \\
\hline Total & $\mathbf{6 2 . 5}$ & $\mathbf{1 7 . 0}$ \\
\hline
\end{tabular}

Table 3 Initial and Final Distribution of Disk Space in Navigator 1.

The equivalent functionality Campus Tour application on Vuman 3 is an hypertext based application, where both system and application software code consume less then $0.35 \mathrm{Mb}$ of Flash Memory Card, distributed as shown in Table 4 . The comparison between the amount of disk space used in Navigator 1 in relation to the amount of flash memory card space used in VuMan 3 clearly indicates that a much smaller amount of secondary storage space is needed for a custom designed computer.

\begin{tabular}{|l|l|}
\hline Category & Space $[\mathrm{kB}]$ \\
\hline Hypertext Viewer & 22.5 \\
\hline String Table & 0.4 \\
\hline Document System Data & 314.0 \\
\hline Total & $\mathbf{3 3 6 . 9}$ \\
\hline
\end{tabular}

Table 4 Distribution of Flash Memory Card Space in VuMan 3.

\subsection{Personpower}

The personpower represents the amount of personnel effort required to complete all phases of the design methodology [3]. Records were kept throughout the Navigator 1 and VuMan 3 projects to evaluate the design methodology. Table 5 and 6 summarize the design effort among phases in the design and between disciplines. Since VuMan 3 represented an evolution of VuMan MA, the technology assessment phase was shorter then for Navigator 1. Due to the custom nature of VuMan 3 the design phase in VuMan 3 required relatively more resources. The relative effort of the electronics group decreased as use of off-the-shelf boards and functionality increased in the Navigator 1 case as shown in Table 6. The VuMan 3 main housing unit with the input dial is almost the same as for VuMan MA, explaining the relatively smaller amount of personal effort put into the mechanical design.

\begin{tabular}{|l|l|l|l|ll|}
\hline Artifact & $\begin{array}{l}\text { Technology } \\
\text { Assessment } \\
\text { (Phase I, II, III) }\end{array}$ & $\begin{array}{l}\text { Design } \\
\text { (Phase IV) }\end{array}$ & $\begin{array}{l}\text { Implementation } \\
\text { and Integration } \\
\text { (Phase V, VI) }\end{array}$ & $\begin{array}{l}\text { Total Effort (Person } \\
\text { Months) }\end{array}$ & \\
\hline $\begin{array}{l}\text { Navigator } \\
\text { I }\end{array}$ & $28 \%$ & $38 \%$ & $34 \%$ & 28 \\
\hline VuMan 3 & $19 \%$ & $48 \%$ & $33 \%$ & 23 \\
\hline
\end{tabular}

Table 5: Distribution of Design Effort for Navigator 1 and VuMan 3

\begin{tabular}{|l|l|l|l|l|}
\hline Artifact & Electronics & Mechanical & Software and HCI & Total Number of Designers \\
\hline $\begin{array}{l}\text { Navigator } \\
\text { I }\end{array}$ & $34 \%$ & $17 \%$ & $49 \%$ & 21 \\
\hline VuMan 3 & $49 \%$ & $16 \%$ & $35 \%$ & 16 \\
\hline
\end{tabular}

Table 6: Distribution of Person effort per discipline 


\subsection{Power management}

Power management can be performed at several levels, from the transistor level in hardware up to the application level in software. A fully custom design can build in features at each level, resulting in a wide range of options for power management. A semi-custom design, using both off-the-shelf and custom components, has fewer power management options available. Because the Navigator 1 was a semi-custom design, we evaluated its power consumption to identify areas for power reduction. Based upon the results of the evaluation, modifications were made to reduce power in the CPU board, the power supply, the hard disk drive, and the A/D board. The battery life and power for several combinations of these modifications were measured. With all the modifications in place, Navigator's battery life was increased from 2.6 hours to 7.5 hours, a factor of 2.9 improvement [12], and power consumption reduced from 15 watts to 7 watts. Figure 6 shows impact of power management on Navigator 1, and Figure 7 illustrates the VuMan 3 power consumption.

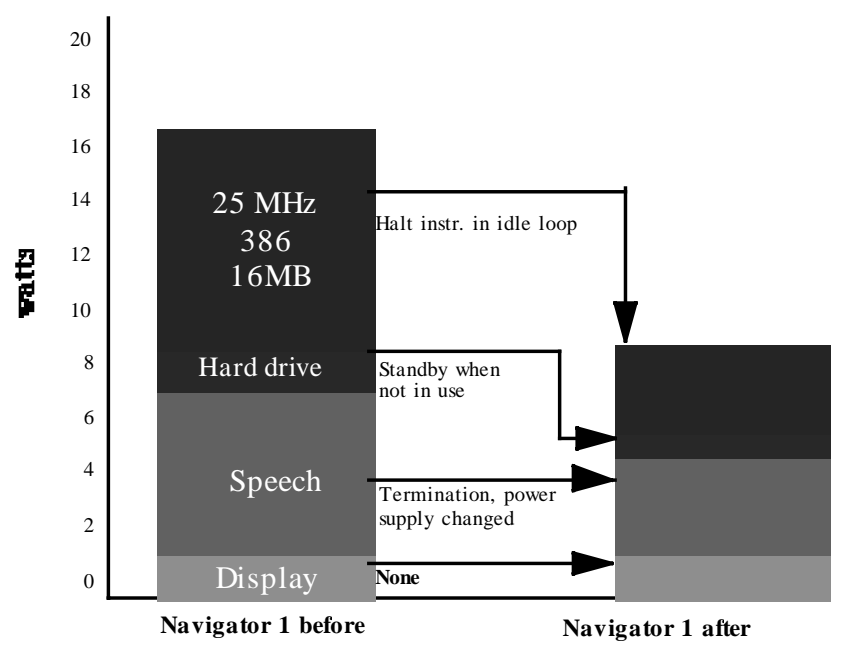

Figure 5. Impact of power management on Navigator 1

The 386EX processor and other components on the VuMan 3's processor board are using the $3.3 \mathrm{~V}$ power supply, what provides considerable power savings over $5 \mathrm{~V}$ components. A programmable PIC $16 \mathrm{C} 71$ microcontroller is used for power management and testing. The PIC microcontroller tests the battery voltage to check if the batteries are running on low voltage, and then turns on colored lights (LEDs). The PIC enables the processor when the power switch is turned on and disables the processor when the switch is turned off. When powered up, the PIC initializes it's internal registers, and then enables the INT interrupt, and goes into sleep mode which uses very little power. Power management software solution can be implemented in a flexible manner. Table 7 compares the power management features for Navigator 1 and VuMan 3. VuMan 3 consumes 1.5 watts, a factor of five less than Navigator 1.

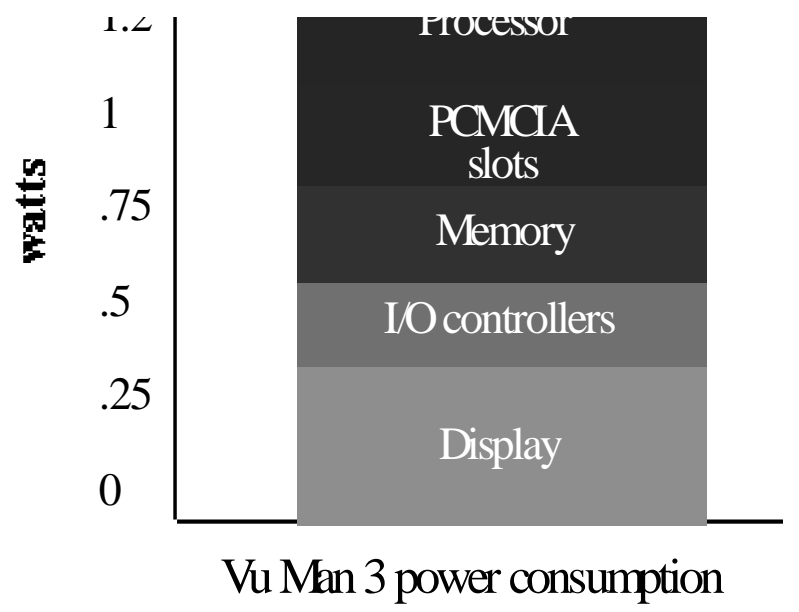

Figure 6. VuMan 3 power consumption 


\subsection{Software Portability}

In porting the software from VuMan MA to VuMan 3,30\% of time was spent on a problem related to different memory addressing schemes, which affected the 386EX low-level initialization, or bootstrap code. VuMan 3 contained over twice as much RAM (volatile memory) than our previous generation of VuMan, (1128kB, as versus $512 \mathrm{kB}$ ). Because of the inherent memory addressing scheme of the 386EX processor, we have to initialize the processor and execute code in the Protected Mode (as it is called by Intel), which would allow us to access memory above the 1MB boundary. As the previous generations of VuMan contained less than 1MB of memory, this problem did not exist. Thus all the low-level/support code for both the bootstrap code, as well as the VuMan hypertext viewer was written for execution in Real Mode (easier to write, but does not access above $1 \mathrm{MB}$ of memory). Therefore, a significant portion of the existing code had to be rewritten to accommodate the increase in memory capacity.

In a general purpose operating system environment, the compilers for protected mode of operation would alleviate this problem to a great extent. Several other implemented tasks depended on the ability to boot up 386EX, so that they could be tested, such as: a new interface to the Private Eye display using one DMA Channel for high-speed data transfer, Real-Time clock, and Silicon Serial Number Chip. Software portability for Navigator 1 and VuMan 3 is evaluated in Table 7.

\begin{tabular}{|l|l|l|}
\hline Attribute & Wearable & Computer \\
\hline & Navigator 1 & VuMan 3 \\
\hline Overhead Factor (\%) & 56.5 & 5.6 \\
\hline Cost (\$) & 4840 & 3550 \\
\hline Person power (months) & 28 & 23 \\
\hline Software Portability & $95 \%$ & $30 \%$ \\
\hline Power (W) & 7.5 & 1.5 \\
\hline
\end{tabular}

Table 7: Attribute comparison

\subsection{Storage requirements}

Storage requirements characterize the amount of secondary storage space needed for system and application software, and data. The space needed on the VuMan 3's PCMCIA Flash EPROM Card was $0.35 \mathrm{MB}$, while the total disk space used by the initial Navigator 1 system was $62.5 \mathrm{MB}$, what is almost fifty times more than in the VuMan 3 case.

\section{Conclusions}

In this paper, we have studied rapid prototyping of Wearable Computers, focusing on custom versus off-the-shelf designs. These computers have a short design cycle, small batch sizes, and close interaction with the users. Based on representative examples from the six generations of the CMU Wearable Computers, we have evaluated both of these design styles. Six attributes characterizing these design styles have been defined: overhead factor, relative cost, storage resources, person power, software portability, and power consumption. The off-the-shelf approach had ten times the overhead, $30 \%$ more cost, fifty times the storage resources, $20 \%$ more effort, five times more power, and 30\% less effort to port software than embedded approach. Kiviat graph on Figure 7 compares these six attributes characterizing custom versus off-the-shelf design. The VuMan 3 user trial results indicated potential savings by reducing maintenance crews from two to one, a decrease of up to $40 \%$ in inspection time due to the elimination of paper handling and the Smart Cursor elimination of input dial motion (Figure 8), a reduction of total inspection/data entry time by up to $70 \%$ by eliminating the database entry to the logistics computer, and savings of over three orders of magnitude in the weight of maintenance documentation. Our results should provide a guide to future designers engaging in the rapid prototyping of real systems. 


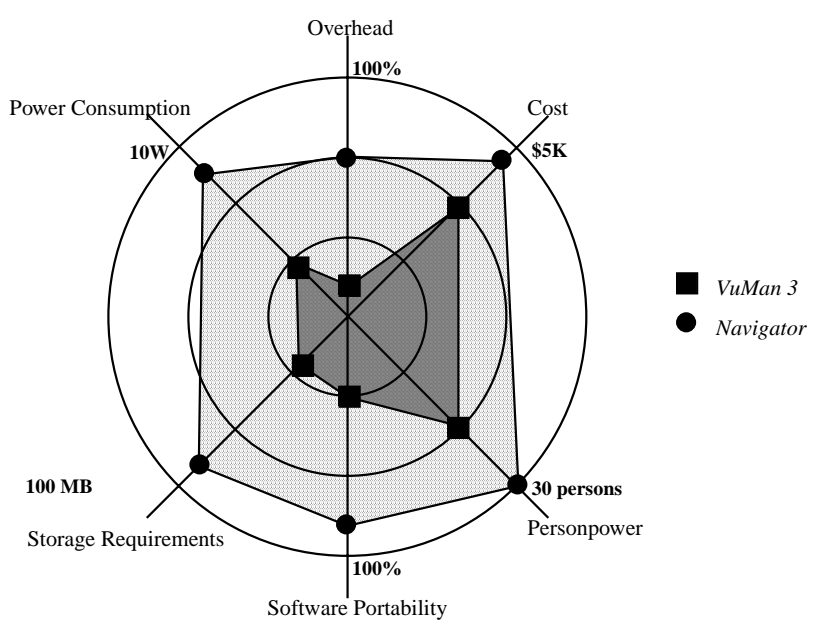

Figure 7: Kiviat Graph with six attributes characterizing custom versus off-the-shelf design

\section{Current Practice SAVING S FACTOR VuMan 3 Field Thials}

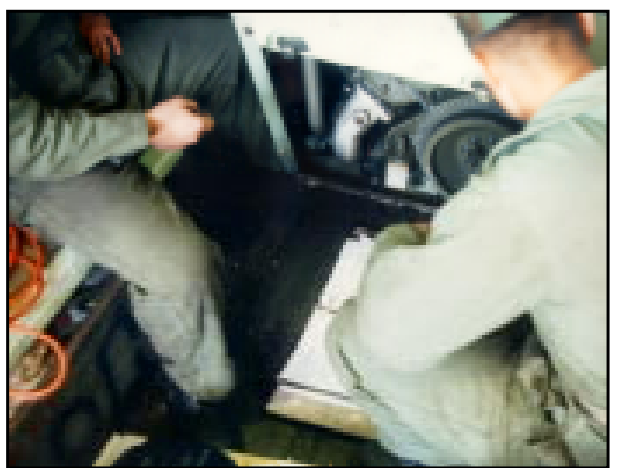

Personnel
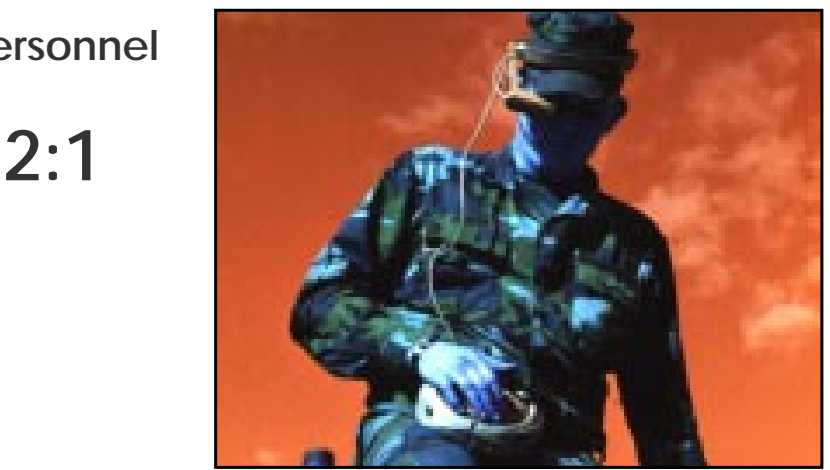

\section{Cument Practice \\ SAVINGS FACTOR \\ VuMan 3 Field Thials}
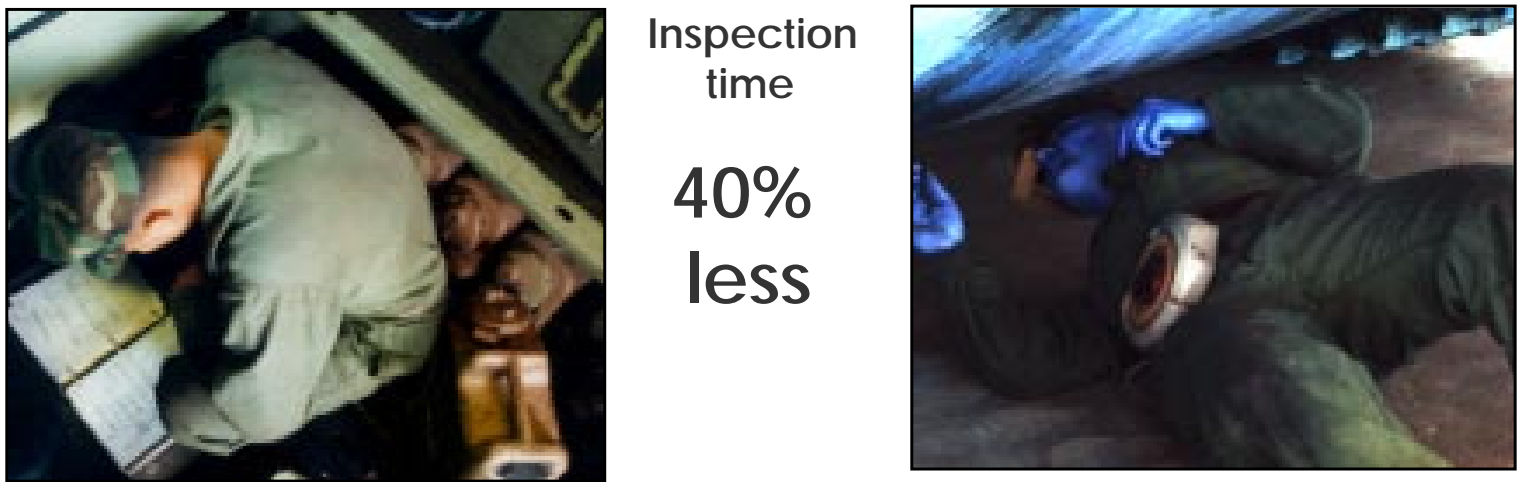

Figure 8. Saving factors for Personnel and Inspection Time

\section{References}

1. J. Akella, A. Dutoit, and D. P. Siewiorek, "Concurrent Engineering: A Prototyping Case Study," Proceedings of the 3rd IEEE International Workshop on Rapid System Prototyping Research Triangle Park, N. Carolina, June 1992.

2. A. Smailagic and D. P. Siewiorek,"A Case Study in Embedded Systems Design: The VuMan 2 Wearable Computer," IEEE Design and Test of Computers, Vol. 10, No. 3, pp. 56-67, September 1993. 
3. D. P. Siewiorek, A. Smailagic, J. C. Y. Lee amd A. R. A. Tabatabai,"Interdisciplinary Concurrent Design Methodology as Applied to the Navigator Wearable Computer System," Journal of Computer and Software Engineering, Vol. 2, No. 3, pp. 259-292, 1994.

4. A. Smailagic and D. P. Siewiorek, "Modalities of Interaction with CMU Wearable Computers," IEEE Personal Communications, Vol. 3, No. 1, pp. 14-25, February 1996.

5. S. Finger, M. Terk, F. Prinz, D. P. Siewiorek, A. Smailagic, J. Stivoric and E. Subrahmanian, "Rapid Design and Manufacture of Wearable Computers", Communications of the ACM, Vol. 39, No. 2, February 1996.

6. A. Smailagic, D. P. Siewiorek, D. Anderson, C. Kasabach, T. Martin and J. Stivoric, "Benchmarking an Interdisciplinary Concurrent Design Methodology for Electronic/Mechanical Systems," Proc. ACM/IEEE Design Automation Conference, pp. 514-519, San Francisco CA, June 1995.

7. A. Smailagic, D. P. Siewiorek, R. Martin and J. Stivoric, "Very Rapid Prototyping of Wearable Computers: A Case Study of Custom versus Off-the-Shelf Design Methodologies," Proc. ACM/IEEE Design Automation Conference, pp. 315-321, Anaheim CA, June 1997.

8. A. Becker, "High Resolution Virtual Displays," Proc. SPIE, Vol. 1664, Society of Photooptical Instrumentation Engineers, Bellingham, Wash., 1992.

9. K. F. Li, H. W. Hon, M. J. Hwang and R. Reddy, "The Sphinx Speech Recognition System," Proceeding of the IEEE ICASSP, Glasgow, UK, May 1989.

10. R. Rashid, et al. "Mach: A System Software Kernel," COMPCON Spring `89, San Francisco, CA, March 1989.

11. MIT X Consortium, X Window System, Version 11, Release 5, MIT Laboratory of Computer Science, Cambridge, MA, 1990.

12. T. Martin,"Evaluation and Reduction of Power Consumption in the Navigator Wearable Computer," Masters Thesis, Report 1-18-94, EDRC, Carnegie Mellon University, July 1994.

13. A. Smailagic and J. Stivoric, "The Cost and Suppliers for Wearable Computers," Engineering Design Research Center Document, Carnegie Mellon University, July 1994.

14. F. Chamberlain, "Secondary Storage for Wearable Computers," Masters Thesis, Report 2-18-94, EDRC, Carnegie Mellon University, July 1994.

This work was supported by the Engineering Design Research Center, an Engineering Research Center of the NSF, under grant no. EEC-894.3164, and the Defense Advanced Research Projects Agency. 